\title{
Oswaldo Caldeira. Café Manduca uma história recontada
}

\author{
Miriam Lifchitz Moreira Leite \\ Pesquisadora aposentada de História Econômica, \\ assessora do Laboratório de Imagem e Som em Antropologia, \\ Depto. de Antropologia, FFLCH/USP; autora de livros \\ e artigos sobre História das Mulheres e Epistemologia da Imagem.
}

Belém: Secult/Oswado. Caldeira Prod. Cinematográficas, 2004, 128p.

Oswaldo Caldeira, cineasta premiado e crítico de cinema, é professor da Escola de Comunicação da Universidade Federal do Rio de Janeiro (UFRJ). Seu roteiro "As histórias de Alice", inspirado na vida de Manduca, seu avô, foi premiado no Concurso Petrobrás Cultural 2004/2005 e está em fase de préprodução.

O livro que ora apresento é a história da família do autor. Publicado com uma diagramação incomum, que chega a dificultar sua identificação, reconta as histórias do Café Manduca, temperadas pelo prazer com que o autor se dedicou à montagem das imagens. Estas provêm de documentação primária, quadros, fotografias, das entrevistas de amigos e contemporâneos, de notícias e anúncios de jornais. Resultam de uma pesquisa cuidadosa, procurando reconstituir o Café Manduca e outras iniciativas de seu avô, através dos anos, das gerações, e das cidades em Portugal e no Brasil.

Hoje, estudos multidisciplinares construíram pontes para que palavra e imagem se complementem, quando a capacidade de sugestão da imagem consegue suprir o poderoso estímulo do que não foi dito, e o texto alimenta e aprofunda o que a imagem sugeriu. São estas combinações de texto e imagens que merecem uma leitura crítica deste livro e das perplexidades que ele traz para o leitor.

A experiência de Oswaldo Caldeira com imagens fixas (as fotografias) e imagens em movimento (documentários históricos) está aqui transposta para uma História da Família. O autor tenta se ocultar por trás das inúmeras vozes que ressoam, mas não as desdobra ou generaliza numa interpretação. Restringiu-se a uma literal montagem, que reconta os textos jornalísticos e os 
depoimentos, intercalando as imagens literárias, plásticas e fotográficas que embelezam o livro.

A mobilização dos inúmeros colecionadores espalhados por toda Belém, professores, jornalistas, garçons, estudantes e curiosos que cercavam a esquina, ou o "canto" escolhido por Manduca para a instalação de seu Café, é que permitiu a reconstituição do cotidiano do movimento do estabelecimento e das ruas ao redor, com sua Casa de Leilões - que se anunciava como situada defronte ao Café Manduca — , além de livrarias, arquivo, jornais e escolas, com uma população masculina atuante, já que sua localização central fazia-o participar do que quer que acontecesse na cidade.

A quantidade e a qualidade das colaborações obtidas diversificaram por demais o andamento e o foco narrativo. Talvez num documentário cinematográfico, com um tempo reduzido de exposição das imagens ao espectador, ficando umas como fundo e outras em primeiro plano, essa diversidade do material não perturbasse a leitura. Num livro em que se vêem ou lêem as imagens e os depoimentos isolados, uns dos outros, essa diversidade dificulta a absorção do sentido. Ao folhear essas belas páginas, pode-se ficar em dúvida sobre do que é que se trata. Da beleza bucólica de Portugal? Da imigração dos portugueses no início do século XX? Da família Corrêa da Silva? Dos empreendimentos e das idéias de Manuel Corrêa da Silva? Da situação sanitária de Santos antes da construção do porto? Da condição sanitária de Belém, antes da eletrificação e das posturas municipais de higiene? Da mobilidade dos imigrantes?

O livro foi escrito por um cineasta e o material reunido era-lhe precioso demais para admitir um peneiramento. Vai sendo apresentado por partes, com diferentes estilos e através de imagens e textos. O personagem principal é o avô Manoel Corrêa da Silva — apelidado de Manduca desde o nascimento em Galafura, Portugal - , rodeado principalmente de mulheres muito corajosas.

Veio para o Brasil com 9 anos de idade, quando seus pais deixaram Portugal em busca de melhores condições de vida. Desembarcaram, com muitos outros portugueses, em Santos, antes da construção das Docas e das reformas urbanas que a tornariam o grande porto do café. Sem preparo algum, Manduca viu-se órfão numa cidade desconhecida, pois o trabalho na remoção do lodo do porto vitimou o pai através da febre amarela. Ajudou, desde então, o sustento da mãe e dos irmãos com os trabalhos pesados e sem horário com que podia arcar, mal chegando a ter uma escolarização digna desse nome.

Quando fez 21 anos, em 1899, casou-se com uma conterrânea de 14, ca- 
paz de ir contra a vontade dos pais para escolher o seu par. Apenas com a força da mocidade e a vontade de vencer enfrentaram a vida em comum longe de suas raízes.

Em 1901 Manduca resolve tentar a vida em Belém do Pará, que vivia o surto da borracha e era, então, das principais cidades brasileiras. Ele e a mulher trabalharam intensamente da madrugada até a noite, cozinhando, empurrando carrinho de entregas, ajudando conterrâneos em açougues e padarias e mostrando-se capazes de enfrentar qualquer tipo de adversidade — para juntar dinheiro.

A decisão e o empenho em melhorar a vida e a crença na capacidade de trabalho deram a eles uma mobilidade, uma capacidade de adaptação e uma sabedoria, independente de suas condições sociais e de escolaridade. Essa melhoria de vida incluía sempre, em quase todos os casos, a ambição de fazer os filhos estudar, fosse nas capitais, nos seminários ou na Europa.

A solidariedade entre imigrantes portugueses fica bem expressa em seus contactos para conhecer a situação econômica e sanitária das cidades brasileiras, como ao se tornar empregado e sócio dos patrícios, estabelecidos anteriormente. Manduca tem garçons portugueses, e o menino de 14 anos, que lhe foi recomendado para o Café, ali ficou por toda a vida, terminando por se tornar seu sócio. A sugestão de que prometera ao pai levar adiante o plano de ascensão social, e a Carolina, dar a ela o que ela quisesse, quando Manduca nada tinha além da juventude e da força de trabalho, simbolizam uma ambição positiva, que só poderia trazer resultados, para aquele homem de um metro de cinqüenta e nove centímetros de altura, por ser ele de uma inteligência extraordinariamente empreendedora.

Antes de abrir o seu café, no centro comercial de Belém, Manduca estudou com o maior empenho o local e as condições em que a sua iniciativa teria êxito: a roupa e a limpeza dos empregados, o capricho do serviço, com tudo brilhando, o modelo original das xícaras, a qualidade dos produtos oferecidos, a necessidade do tratamento cordial dos fregueses e da apresentação de novidades. Rodeado por redações dos principais jornais, Manduca pôde verificar nos exemplares deixados no Café que todos os vizinhos, das duas ruas, faziam anúncios de seus negócios. Discutiu com os jornalistas a eficácia e as vantagens que um anúncio poderia trazer. Verificou que não só se tornaria conhecido de muito mais pessoas, além das que já freqüentavam seu café, como se destacaria dos concorrentes. Além disso, teria melhor relacionamento com os diretores dos principais jornais de Belém. Iniciou, então, uma série de anúncios personalizados, chamando a atenção para a excelência do esta- 
belecimento e para as novidades com que contribuía para o conforto de seus freqüentadores. Acompanhando o progresso tipográfico dos jornais, os anúncios foram crescendo e, de pequenas notas, passaram a tomar maior espaço e ser ilustrados por desenhos das melhorias introduzidas para aperfeiçoamento de seus produtos: a importação de um técnico do Sul, para a moagem do café, os carrinhos comprados para sua distribuição e uma bem montada vaccaria, que posteriormente torna-se um estábulo, com endereço próprio, para garantir a qualidade do leite. Mesmo sendo o café um ambiente exclusivamente masculino, aparece uma figura de mulher saboreando o produto distribuído pela cidade.

Em 1908 foi publicado O Pará Manufactureiro, redigido para a Exposição Nacional. Pretendia reunir todos os produtos das indústrias agrícolas e pastoris, manufatureiras e outras, de artes liberais, para avaliar as forças produtivas do país numa exposição no Rio de Janeiro. Nessa publicação o Café Manduca apareceu como o mais afamado e popular estabelecimento de beneficiar café de todo o Norte do país.

A partir de então, a vida de Manduca se transformou. Adquiriu propriedades no Rio de Janeiro e passou a freqüentar a Igreja Presbiteriana, e foi, com toda a família, batizado nessa crença. É a partir de então que se faz registrar de terno e gravata, sempre em imagens obtidas nos principais fotógrafos das cidades (Rio de Janeiro e Porto), atestando sua ascensão social. Depois dos anúncios, são as fotografias que passam a registrar a sua memória e a de sua família, com notas que comunicam entre os "Fatos e Comentos" do jornal $O$ Puritano (Rio de Janeiro) da Primeira Igreja Presbiteriana, os novos filhos e as novas iniciativas. Na cidade do Porto, para onde se retirou em 1914, fundou o Portugal Evangélico que, mais do que recuperar uma fábrica de calçados falida a que deu o nome de Atlas, era uma renovação improvável do menino descalço e analfabeto, que aos nove anos se viu órfão e encarregado de cuidar da mãe e dos irmãos em Santos.

Essa História Recontada é construída pela complementaridade do texto visual e do texto verbal. Os aspectos da pobreza, do sofrimento e da doença ficam atenuados pelos recursos tecnológicos da fotografia bem utilizados: o ângulo, a cor, a distância, a ausência do odor e a dissimulação da sujeira. Em Café Manduca, a beleza e a tranqüilidade das imagens iniciais das margens do Doiro e da Igreja de São Vicente de Galafura são acentuadas pelas passagens poéticas de Miguel Torga. Já as belas reproduções do porto de Santos, em 1882 e 1888, do artista local Benedicto Calixto, com aquela floresta de mastros e a harmonia da vista do casario santista de anos depois, velam inteiramente a 
situação de insalubridade daqueles mangues, antes das obras de saneamento e da construção do porto, onde uma epidemia de febre amarela foi completada por um surto de varíola. Os cortiços onde iam-se amontoando os imigrantes ficam soterrados no colorido dos quadros. A fotografia em preto e branco de imigrantes, com seus sacos e baús e fisionomias carregadas, que o livro também apresenta, é mais representativa da situação penosa que o texto depois revela, sobre a instalação precária e a mobilidade dos recém-chegados.

No início do século XX, o chefe de família resolve se transferir de um lugar para outro, de Santos para Belém, de Belém para o Rio de Janeiro, do Rio para o Porto, em Portugal, sem que os membros da família saibam o que o levou a tomar as resoluções e as mudanças de casa e de país.

Os depoimentos não revelam apenas apresentações subjetivas de freqüentadores do café, mas demonstram como sua localização, no centro comercial e político de Belém, foi um fator decisivo para o sucesso. Em seus 55 anos de vida, o café foi um local privilegiado de sociabilidade masculina, reunindo personagens que o consideravam sob diferentes óticas. A freqüência de políticos e jornalistas o tornou cenário de reflexões e intrigas, tendo até havido a ameaça de ser fechado por suspeita de ser um centro de conspirações. Os Vilhena, que ficaram com o café quando Manduca voltou para Portugal, ainda mantiveram essa situação - eram chamados de Os Manducas e criaram um time de futebol, o Manduquinha Futebol Clube.

Os retratos envelhecidos, reunidos do interior do café e preservados por Orlando Vilhena, filho do sócio de Manduca, são registros dos empregados e de uma figura mítica que passara a fazer parte dele: o engraxate e corredor que recitava a Divina comédia e era o próprio historiador da casa. A profusão de documentos, fotos e recortes de jornal que Orlando Vilhena proporcionou ao neto de Manduca significava para ele a história da família Vilhena, pois o pai viera com 14 anos e ali ficou até o fim da vida. Diversificou a produção da casa com charutos e polpa de tamarindo, e observou que a presença de jornalistas, estudantes de engenharia e políticos já começava a ser diferenciada pela companhia das mulheres que agora trabalhavam nos escritórios.

Nessa parte do livro as fotografias pouco acrescentam, tanto os instantâneos do interior do café quanto as fotos coloridas das ruas ao redor. Algumas, como a que ilustra "o crime da barba inacabada", é uma reprodução de um jornal que só nos revela o uso cotidiano das palhetas (chapéu de palha urbano, da década de 1930). O texto, habilmente composto pelo autor com as diferentes versões dadas ao episódio, é que nos informa sobre o evento fatal para José Avelino, presidente da União Auxiliadora dos Estivadores do Lloyd 
Brasileiro, que interferiu desastradamente num conflito das facções baratistas e frente-unistas.

Os depoimentos são uma fonte riquíssima para o conhecimento da história dos jornais de Belém, de seus personagens e de seu funcionamento precário, dependente da política local e dedicado à preservação das ocorrências locais.

Esta leitura do livro de Oswaldo Caldeira, empreendida para demonstrar a complementaridade dos textos verbais e dos textos visuais, termina privilegiando o texto verbal de um especialista em imagens em movimento. É, contudo, um exemplo significativo de que é preciso avaliar a adequação da imagem ao que se quer transmitir, e de que às vezes o texto verbal é a melhor opção. Antes ainda, é preciso conhecer a intenção do autor: a procura do melhor meio de transmitir os resultados de sua pesquisa. Mas as análises que a Antropologia nos ensina não são as únicas formas de combinar adequadamente imagens e palavras para aperfeiçoar a compreensão do material publicado. É possível querer unicamente reunir imagens que correspondem à memória do autor. É também possível ter o desejo de fascinar o leitor pela beleza ou pelo pitoresco das imagens. Ocorre também o caso de desejar desmentir pela imagem o que o texto verbal expressou, ou complementar-lhe o sentido.

Resenha recebida em 02/2005. Aprovada em 05/2005 